\title{
Arginine metabolism and its protective effects on intestinal health and functions in weaned piglets under oxidative stress induced by diquat
}

\author{
Ping Zheng ${ }^{1,2}$, Bing $\mathrm{Yu}^{1,2}$, Jun $\mathrm{He}^{1,2}$, Jie $\mathrm{Yu}^{1,2}$, Xiangbing $\mathrm{MaO}^{1,2}$, Yuheng $\mathrm{Luo}^{1,2}$, Junqiu Luo ${ }^{1,2}$, \\ Zhiqing Huang ${ }^{1,2}$, Gang Tian ${ }^{1}$, Qiufeng Zeng ${ }^{1}$, Lianqiang Che ${ }^{1,2}$ and Daiwen Chen ${ }^{1,2_{*}}$ \\ ${ }^{1}$ Animal Nutrition Institute, Sichuan Agricultural University, Xinkang Road 46\#, Ya'an, Sichuan Province 625014, People's \\ Republic of China \\ ${ }^{2}$ Animal Disease-Resistance Nutrition Key Laboratory of Sichuan Province, Ya'an 625014, People's Republic of China
}

(Submitted 25 January 2017 - Final revision received 23 May 2017 - Accepted 27 May 2017)

\section{Abstract}

The intestine plays key roles in maintaining body arginine (Arg) homoeostasis. Meanwhile, the intestine is very susceptible to reactive oxygen species. In light of this, the study aimed to explore the effects of Arg supplementation on intestinal morphology, Arg transporters and metabolism, and the potential protective mechanism of Arg supplementation in piglets under oxidative stress. A total of thirty-six weaned piglets were randomly allocated to six groups with six replicates and fed a base diet (0.95\% Arg,) or base diet supplemented with $0.8 \%$ and $1.6 \%$ L-Arg for 1 week, respectively. Subsequently, a challenge test was conducted by intraperitoneal injection of diquat, an initiator of radical production, or sterile saline. The whole trial lasted $11 \mathrm{~d}$. The diquat challenge significantly decreased plasma Arg concentration at $6 \mathrm{~h}$ after injection $(P<0.05)$, lowered villus height in the jejunum and ileum $(P<0.05)$ as well as villus width and crypt depth in the duodenum, jejunum and ileum $(P<0 \cdot 05)$. Oxidative stress significantly increased cationic amino acid transporter $(C A T)-1, C A T-2$ and CAT-3, mRNA levels $(P<0.05)$, decreased arginase II (ARGII) and inducible nitric oxide synthase mRNA levels, and increased TNF- $\alpha$ mRNA level in the jejunum $(P<0.05)$. Supplementation with Arg significantly decreased crypt depth $(P<0.05)$, suppressed $C A T-1$ mRNA expression induced by diquat $(P<0 \cdot 05)$, increased $A R G I$ and endothelial nitric oxide synthase mRNA levels $(P<0.05)$, and effectively relieved the TNF- $\alpha$ mRNA expression induced by diquat in the jejunum $(P<0.05)$. It is concluded that oxidative stress decreased Arg bioavailability and increased expression of inflammatory cytokines in the jejunum, and that Arg supplementation has beneficial effects in the jejunum through regulation of the metabolism of Arg and suppression of inflammatory cytokine expression in piglets.

Key words: Arginine: Intestines: Metabolism: Oxidative stress: Weaned piglets

It is well known that oxidative stress can be very harmful to mammalian tissues, particularly the intestine ${ }^{(1,2)}$. Health status is significantly affected and performance is decreased because of oxidative stress in pigs ${ }^{(3-7)}$. Weanling piglets are subjected to various challenges, such as change in the nutritional source, feed contamination with mycotoxins, pathogenic micro-organisms and some chemical agents as well as the use of drugs and vaccine factors, which might produce excessive amounts of reactive oxygen species (ROS) and induce oxidative stress ${ }^{(8,9)}$. Oxidative stress induces cell apoptosis, inhibits cell proliferation, suppresses intestinal development and disturbs intestinal function $^{(10-13)}$. Further, the intestinal cells are rich in mitochondria ${ }^{(14)}$, which are the main sites for ROS generation ${ }^{(15)}$. At the same time, the intestine is highly susceptible to oxidative damage because of its frequent interaction with $\mathrm{O}_{2}$ metabolism or luminal oxidants from the intake of nutrients, micro-organisms or through infections ${ }^{(16,17)}$

L-Arginine (L-Arg) is not only an essential amino acid in young piglets but also a functional amino acid. Numerous research studies show that L-Arg can function as a potential substance against oxidative stress ${ }^{(18-21)}$. Our previous study showed that supplementation with Arg can ameliorate the negative effect induced by diquat, an initiator of ROS production, through the enhancement of antioxidant capacity and attenuation of negative effects of feed intake in piglets ${ }^{(5)}$. The intestine plays a key role in Arg absorption, endogenous synthesis and metabolism in addition to functioning as the site for maintaining Arg homoeostasis $^{(22)}$. Studies show that Arg is predominantly transported across the intestinal membrane via $\mathrm{Na}^{+}$-independent cationic amino acid transporters (CAT) including CAT-1, CAT-2 and

Abbreviations: Arg, arginine; ARGII, arginase II; ArgH, basal diet and supplementation with 1.6\% synthetic L-Arg; ArgL, basal diet; ArgM, basal diet and supplementation with $0.8 \%$ synthetic L-Arg; CAT, cationic amino acid transporter; eNOS, endothelial nitric oxide synthase; iNOS, inducible nitric oxide synthase; NO, nitric oxide.

* Corresponding author: D. Chen, fax +86 835 2882088, email dwchen@sicau.edu.cn 
CAT-3 isoforms ${ }^{(23,24)}$. Changes in Arg transport activity in the intestine reflect the status of Arg metabolism in intestines as well as in the whole body. Research studies also found that catabolic disease increased intestinal Arg transport in rats and in Caco-2 cell cultures $^{(24)}$. Besides, the intestine is the most important site for Arg and citrulline synthesis by pyrroline-5-carboxylate (P5C) synthase ${ }^{(25)}$, because other major tissues including the liver, kidney and skeletal muscle lack P5C synthase for synthesising citrulline from glutamine or glutamate ${ }^{(26)}$. As arginase and nitric oxide (NO) synthase use Arg as the common substrate, arginase may play a role in regulating $\mathrm{NO}$ synthesis by modulating Arg availability ${ }^{(27,28)}$. Therefore, Arg availability is regulated by many factors, and dietary Arg supplementation may be a necessary strategy to maintain Arg homoeostasis for good health and body functions under many physiological and pathological conditions ${ }^{(29)}$.

Our previous studies already found that oxidative stress decreased the level of Arg in circulation in piglets ${ }^{(30)}$, and supplementation with Arg could attenuate oxidative stress by enhancing the total antioxidative capacity in piglets ${ }^{(5)}$. However, little is known about the effect of dietary Arg supplementation on Arg metabolism in the intestine under oxidative stress conditions in piglets. The aim of this study was to investigate the effects of supplementation with Arg on Arg transport and metabolism, and potential mechanisms underlying the Arg-induced protective effects in the intestine under the oxidative stress conditions in piglets

\section{Methods}

\section{Experimental animals and diets}

The samples for the current study were obtained from the animal experiment conducted in our previous study. The experimental piglets and diets are described in detail in our previous study ${ }^{(5)}$. In brief, a total of thirty-six crossbred weaned male piglets (8.67 (sem 0.43) kg, 28 (sem 1) d) (Pig Improvement Company, PIC) were housed individually and randomly allocated into six groups with six replicates per group ( $n$ 6). Piglets were subjected to three dietary treatments (two groups per treatment) in the 1st week and fed a basal diet supplemented with varying concentrations of Arg. The diets were the same as in our previous report ${ }^{(5)}$. Dietary treatments were as follows: basal diet (ArgL), basal diet and supplementation with $0.8 \%$ synthetic L-Arg (ArgM) and basal diet and supplementation with $1.6 \%$ synthetic L-Arg $(\operatorname{ArgH})$.

\section{Experimental procedure}

The experimental procedure was the same as in our previous study ${ }^{(5)}$. In brief, at 08.00 hours on day 8 , piglets in each dietary treatment were intraperitoneally injected with diquat at a concentration of $10 \mathrm{mg} / \mathrm{kg}$ body weight or with a sterile $0.9 \% \mathrm{NaCl}$ solution of the same amount, respectively. Diquat (Diquat dibromide monohydrate, PS365; Sigma, Co.) was dissolved in isotonic saline and filter-sterilised. The concentration of the diquat solution was $10 \mathrm{mg} / \mathrm{ml}$. The whole trial lasted for $11 \mathrm{~d}$. This study was approved by the Animal Care Advisory committee of Sichuan Agricultural University.

\section{Blood sampling and analyses}

Before injection $(0 \mathrm{~h})$ and at 6, 24, 48 and $96 \mathrm{~h}$ post injection, a blood sample $(10 \mathrm{ml} / \mathrm{pig})$ was collected from the portal vein precava into heparinised polyethylene tubes (Axygen biotechnology Co., Ltd). Plasma was prepared by centrifuging the blood $\left(3000 \mathrm{~g}\right.$ at $4{ }^{\circ} \mathrm{C}$ for $15 \mathrm{~min}$ ) and immediately stored at $-20^{\circ} \mathrm{C}$.

Plasma Arg concentration was assayed using the amino acid automatic analyser L8800 (Hitachi). Frozen plasma samples were thawed at $4{ }^{\circ} \mathrm{C}$ and $3 \mathrm{ml}$ of a $10 \%(\mathrm{w} / \mathrm{v})$ solution of sulfosalicylic acid was added to $1 \mathrm{ml}$ of plasma sample and centrifuged $\left(12000 \boldsymbol{g}\right.$ for $1 \mathrm{~h}$ ) at $4^{\circ} \mathrm{C}$. The Arg concentration of deproteinised plasma was determined by ion-exchange chromatography ${ }^{(31)}$.

\section{Tissue sample collection}

After the blood was collected at $96 \mathrm{~h}$ post injection, piglets were euthanised with an intravenous injection of pentobarbital sodium $(50 \mathrm{mg} / \mathrm{kg}$ body weight) and then slaughtered by exsanguination protocols approved by the Sichuan Agricultural University Animal Care Advisory Committee.

A midline laparotomy was performed. The abdomen was incised, and the entire small intestine starting from the pylorus to the ileocaecal valve was removed and divided into three segments: duodenum, jejunum and ileum. The segment from the pylorus to the suspensory muscle of duodenum was defined as duodenum, the last three-fifths segment was defined as ileum, and the middle segment was defined as jejunum. Segments of $2 \mathrm{~cm}$ length were cut from the middle of the duodenum, jejunum and ileum, respectively. The segments were flushed gently with ice-cold PBS (pH 7.4) and then fixed in 10\% fresh, chilled formalin solution. Following this, $0.5 \mathrm{~cm}$ jejunum samples were removed and snap-frozen in $\mathrm{N}_{2}$ and then stored at $-80^{\circ} \mathrm{C}$ until RNA isolation.

\section{Intestinal morphology analysis}

The samples were fixed in neutral-buffered formaldehyde, embedded and stained according to the method of Luna ${ }^{(32)}$. The sections were stained with haematoxylin-eosin. In each section, villus height, villus width and crypt depth were examined in ten well-orientated villi and crypts using an Olympus CK 40 microscope (Olympus Optical Company).

\section{Intestinal gene expression}

Total RNA was extracted from samples of the jejunum using the TRIzol reagent (TaKaRa), according to the manufacturer's instructions. The concentration of RNA in the final preparations was calculated from the OD260. The integrity of RNA was verified using denaturing agarose gel electrophoresis. Reverse transcription was performed using the Prime Script ${ }^{\mathrm{TM}}$ RT reagent Kit (TaKaRa) with a $2-\mu \mathrm{g}$ RNA sample, according to the manufacturer's instructions. Complementary DNA was used as the template for PCR.

Real-time quantitative PCR was performed in an Option Monitor 3 Real-Time PCR Detection System (Bio-Rad) using the SYBR Green Supermix (TaKaRa). Expression levels of 
CAT-1, CAT-2, CAT-3, arginase II (ARGII), inducible nitric oxide synthase (iNOS), endothelial nitric oxide synthase (eNOS), IL-6, TNF- $\alpha$ and PPAR- $\gamma$ in the jejunum were analysed using real-time quantitative PCR with SYBR Green PCR reagents (TaKaRa) carried out in the Option DNA Engine (Bio-Rad) using the following cycle parameters: $95^{\circ} \mathrm{C}$ for $10 \mathrm{~s}$, followed by forty cycles at $95^{\circ} \mathrm{C}$ for $5 \mathrm{~s}$, annealing temperature (Table 1) for $20 \mathrm{~s}$, and a final extension at $72^{\circ} \mathrm{C}$ for $15 \mathrm{~s}$. The gene-specific primers used are listed in Table 1. All primers were purchased from TaKaRa. Fluorescence detection was carried out immediately at the end of each annealing step, and the purity of the amplification was confirmed by analysing the melting curves. Gene expression relative to the housekeeping gene $\beta$-actin was measured in order to correct for the variance in amounts of RNA input in the reactions. $\beta$-Actin was used as the reference gene according to the stability test of Hillig et $a{ }^{(33)}$.

Each primer pair used yielded a single peak in the melting curve and a single band of the expected size in the agarose gel. The relative gene expression levels compared with the housekeeping gene $\beta$-actin were calculated using the Pfaffl (2001) method $^{(34)}$

\section{Statistical analysis}

Data were analysed by two-way ANOVA using the general linear model procedure. The main effects of the model included Arg supplementation levels (0, 0.8 and 1.6\%) and oxidative stress processing (injection of diquat or saline). $P<0.05$ was considered to indicate a significant difference and values between 0.05 and $0 \cdot 10$ to indicate a trend. Variable means for treatments showing significant differences in ANOVA were separated by Duncan's test $(P<0 \cdot 05)$. Values were expressed as means with their standard errors. All statistical analysis was performed using SPSS17.0.

\section{Results}

\section{Concentrations of plasma arginine}

The data on plasma Arg are shown in Table 2. Compared with the basal diet, supplementation with Arg had no significant influence on plasma Arg concentration $(P>0.05)$. Injection of diquat resulted in an acute reduction in plasma Arg concentration at $6 \mathrm{~h}$ after diquat injection $(P<0.05)$. There was no significant effect of interaction between Arg supplementation and injection of diquat on Arg concentration.

\section{Intestinal morphology}

Data on morphology of the small intestine are shown in Table 3. Injection of diquat resulted in a reduction of villus height in the jejunum and ileum $(P<0.05)$ as well as in villus width and crypt depth in the duodenum, jejunum and ileum $(P<0.05)$. Supplementation with Arg (ArgM and ArgH) significantly decreased crypt depth in the jejunum with or without injection of diquat $(P<0.05)$. There was no significant interaction effect of Arg supplementation and injection of diquat on intestinal morphology.

\section{Cationic amino acid transporter gene expressions in the jejunum}

As shown in Fig. 1, supplementation with Arg had no effect on $C A T-1$ mRNA level in the jejunum $(P>0.05)$ under non-oxidative stresses conditions. Injection of diquat significantly increased CAT-1 mRNA level $(P<0.05)$, whereas supplementation with Arg along with injection of diquat in the jejunum significantly decreased CAT-1 mRNA level $(P<0.05)$.

ArgM significantly increased CAT-2 mRNA level in the jejunum compared with $\operatorname{ArgL}$ without injection of diquat $(P<0.05)$, and injection of diquat significantly increased $C A T-2$ mRNA level compared with injection of saline $(P<0.05)$.

Table 1. Primers used for real-time analyses

\begin{tabular}{|c|c|c|c|c|}
\hline Gene names & Primer sequence $5^{\prime}-3^{\prime}$ & Product size (bp) & $\begin{array}{c}\text { Annealing } \\
\text { temperature }\left({ }^{\circ} \mathrm{C}\right)\end{array}$ & Accession no. \\
\hline CAT-1 & $\begin{array}{l}\text { F: gagcaagaccaaactctccttc } \\
\text { R: agcctatcagcatccacactg }\end{array}$ & 137 & $57 \cdot 2$ & NM_001012613 \\
\hline CAT-2 & $\begin{array}{l}\mathrm{F}: \text { agtgagtaagaggcagtcaccag } \\
\mathrm{R} \text { : accagagagtaggccagaagg }\end{array}$ & 135 & 61 & EU155140 \\
\hline CAT-3 & $\begin{array}{l}F: \text { gaggaacgaggaaggtgaagt } \\
\text { R: aggacactcagcagtagagcaag }\end{array}$ & 165 & $60 \cdot 6$ & NM_001130973 \\
\hline eNOS & $\begin{array}{l}\text { F: acaggctctcaccttcttcct } \\
\text { R: aaccacttccactcctcatagc }\end{array}$ & 150 & 61 & NM_214295 \\
\hline iNOS & $\begin{array}{l}\text { F: acaccccaaatacgagtggttc } \\
\text { R: cccatgtaccagccattgaag }\end{array}$ & 129 & 61 & U59390 \\
\hline ARGII & $\begin{array}{l}F: \text { gtcagtagagcggtgtcaggt } \\
R: \text { gatgaagtggtgaggggtgtat }\end{array}$ & 161 & 60 & XM_001928679 \\
\hline$T N F-a$ & $\begin{array}{l}\text { F: gctcttctgcctactgcacttc } \\
\text { R: ggcttatctgaggtttgagacg }\end{array}$ & 123 & 61 & X57321 \\
\hline IL-6 & $\begin{array}{l}\text { F: ggagacctgcttgatgagaatc } \\
\text { R: gtactaatctgcacagcctcgac }\end{array}$ & 117 & 61 & M80258 \\
\hline PPAR- $\gamma$ & $\begin{array}{l}\text { F: ccagcatttccactccacacta } \\
\text { R: gacacaggctccactttgatg }\end{array}$ & 124 & 58 & AJ006757 \\
\hline$\beta$-Actin & $\begin{array}{l}\text { F: ccacgaaactaccttcaactcc } \\
\text { R: gtgatctccttctgcatcctgt }\end{array}$ & 132 & 60 & DQ845171 \\
\hline
\end{tabular}

CAT, cationic amino acid transporter; eNOS, endothelial nitric oxide synthase; iNOS, inducible nitric oxide synthase; ARGII, arginase II. 
Table 2. Effects of arginine (Arg) supplementation and diquat injection on the concentration of $\operatorname{Arg}$ in the plasma of piglets $(\mathrm{nmol} / \mathrm{ml})^{\star}$

\begin{tabular}{|c|c|c|c|c|c|c|c|c|c|c|}
\hline \multirow[b]{2}{*}{ Responses } & \multicolumn{3}{|c|}{ SS } & \multicolumn{3}{|c|}{ os } & \multirow[b]{2}{*}{ SEM } & \multicolumn{3}{|c|}{ Analysis by effect $(P)$} \\
\hline & ArgL & ArgM & $\mathrm{ArgH}$ & ArgL & ArgM & $\mathrm{ArgH}$ & & Arg & os & $\operatorname{Arg} \times \mathrm{OS}$ \\
\hline $\mathrm{Oh}$ & $46 \cdot 4$ & $55 \cdot 7$ & $38 \cdot 3$ & - & - & - & 4.03 & 0.335 & - & - \\
\hline $6 \mathrm{~h}$ & $65 \cdot 6$ & $80 \cdot 5$ & 68.2 & 39.6 & $58 \cdot 6$ & $58 \cdot 7$ & 4.42 & 0.267 & 0.031 & 0.711 \\
\hline $24 \mathrm{~h}$ & $50 \cdot 0$ & $34 \cdot 3$ & 35.5 & 46.5 & $40 \cdot 8$ & 42.2 & $2 \cdot 22$ & 0.108 & 0.461 & 0.559 \\
\hline $48 \mathrm{~h}$ & $32 \cdot 0$ & 33.4 & 30.2 & $33 \cdot 6$ & $30 \cdot 1$ & 33.7 & $1 \cdot 19$ & 0.932 & 0.806 & 0.522 \\
\hline $96 \mathrm{~h}$ & $22 \cdot 0$ & $24.8 \mathrm{c}$ & 22.9 & $25 \cdot 6$ & 25.4 & $22 \cdot 7$ & 1.06 & 0.711 & 0.560 & 0.733 \\
\hline
\end{tabular}

SS, injection with sterile saline; OS, injection with diquat; ArgL, basal diet; ArgM, basal diet and supplementation with 0.8\% synthetic L-Arg; ArgH, basal diet and supplementation with $1.6 \%$ synthetic L-Arg; Arg $\times$ OS, Arg $\times$ OS interaction effect.

* $0 \mathrm{~h}, n 12$, others, $n 6$.

Table 3. Effects of arginine (Arg) supplementation on villus height, villus width and crypt depth of weaned piglets after $96 \mathrm{~h}$ oxidative stress induced by diquat, $n 6$

\begin{tabular}{|c|c|c|c|c|c|c|c|c|c|c|}
\hline \multirow[b]{2}{*}{ Responses } & \multicolumn{3}{|c|}{ SS } & \multicolumn{3}{|c|}{ OS } & \multirow[b]{2}{*}{ SEM } & \multicolumn{3}{|c|}{ Analysis by effect $(P)$} \\
\hline & ArgL & ArgM & ArgH & ArgL & ArgM & ArgH & & Arg & OS & $\operatorname{Arg} \times \mathrm{OS}$ \\
\hline \multicolumn{11}{|c|}{ Villus height $(\mu \mathrm{m})$} \\
\hline Duodenum & 367 & 373 & 411 & 293 & 342 & 353 & 17 & 0.495 & 0.115 & 0.797 \\
\hline Jejunum & $302^{b}$ & $387^{a}$ & $406^{a}$ & $295^{\mathrm{b}}$ & $295^{\mathrm{b}}$ & $292^{b}$ & 14 & 0.221 & 0.004 & 0.109 \\
\hline Ileum & $388^{a}$ & $378^{a, b}$ & $315^{\mathrm{b}, \mathrm{c}}$ & $288^{\mathrm{C}}$ & $283^{c}$ & $320^{b, c}$ & 11 & 0.741 & 0.002 & 0.067 \\
\hline \multicolumn{11}{|c|}{ Villus width $(\mu \mathrm{m})$} \\
\hline Duodenum & $127^{\mathrm{a}}$ & $130^{\mathrm{a}}$ & $132^{a}$ & $120^{a, b}$ & $99^{\mathrm{b}}$ & $113^{a, b}$ & 3 & 0.387 & 0.002 & 0.266 \\
\hline Jejunum & $139^{a}$ & $139^{\mathrm{a}}$ & $123^{a, b}$ & $94^{\mathrm{b}}$ & $105^{\mathrm{b}}$ & $105^{b}$ & 5 & 0.659 & 0.018 & 0.926 \\
\hline Ileum & 131 & 127 & 128 & 111 & 107 & 112 & 3 & 0.611 & 0.008 & 0.948 \\
\hline \multicolumn{11}{|c|}{ Crypt depth $(\mu \mathrm{m})$} \\
\hline Duodenum & 381 & 359 & 349 & 343 & 299 & 306 & 10 & 0.282 & 0.022 & 0.899 \\
\hline Jejunum & $268^{a}$ & $148^{b, c}$ & $163^{b, c}$ & $184^{\mathrm{b}}$ & $118^{\mathrm{c}}$ & $106^{c}$ & 12 & $<0.001$ & $<0.001$ & 0.200 \\
\hline Ileum & $258^{a}$ & $260^{a}$ & $245^{a}$ & $206^{a, b}$ & $230^{a, b}$ & $192^{b}$ & 9 & 0.873 & 0.004 & 0.640 \\
\hline
\end{tabular}

SS, injection with sterile saline; OS, injection with diquat; ArgL, basal diet; ArgM, basal diet and supplementation with $0.8 \%$ synthetic L-Arg; ArgH, basal diet and supplementation with $1.6 \%$ synthetic L-Arg; Arg $\times$ OS, Arg $\times$ OS interaction effect.

a,b,c Mean values within a row with unlike superscript letters were significantly different $(P<0.05)$.
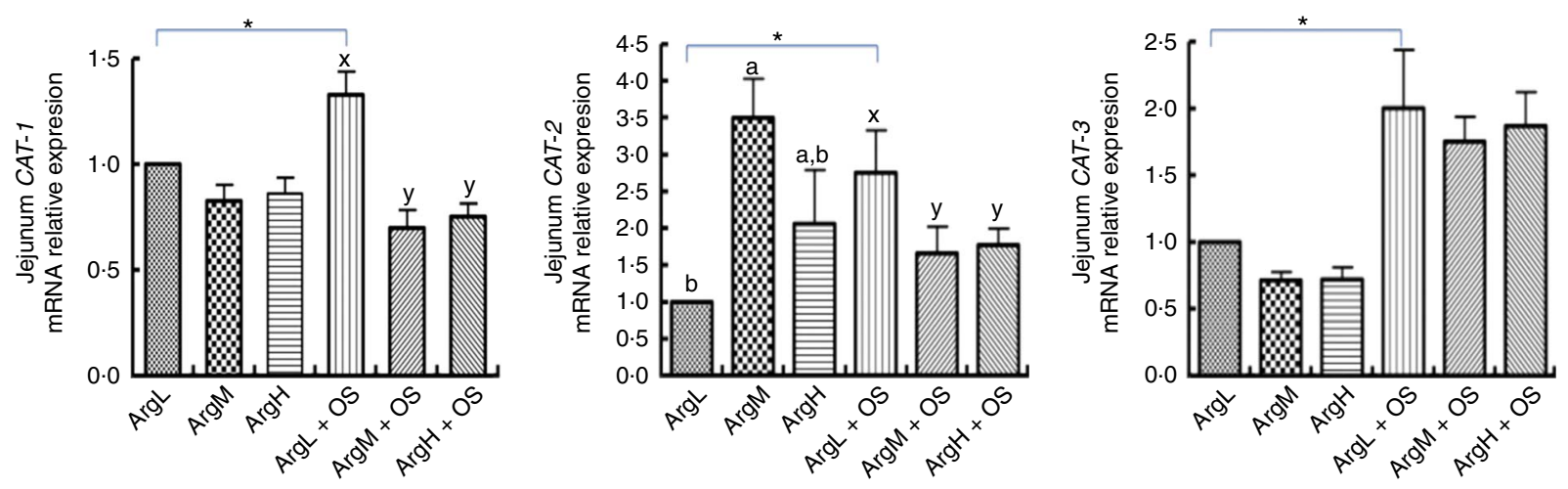

Fig. 1. Effects of arginine (Arg) supplementation and diquat injection on relative expressions of CAT-1, CAT-2 and CAT-3 mRNA in the jejunum of piglets. CAT, cationic amino acid transporter; ArgL, basal diet; ArgM, basal diet and supplementation with $0.8 \%$ synthetic L-Arg; ArgH , basal diet and supplementation with $1.6 \%$ synthetic L-Arg; OS, injection with diquat. Values are means $(n 6)$, with their standard errors represented by vertical bars. ${ }^{\mathrm{x}, \mathrm{y}}$ or ${ }^{\mathrm{a}, \mathrm{b}}$ Mean values with unlike superscript letters were significantly different $(P<0.05)$. ${ }^{*}$ Mean values were significantly different between two groups $(P<0.05)$.

Supplementation with Arg had no effect on CAT-3 mRNA level in the jejunum $(P>0.05)$ but injection of diquat significantly increased $C A T-3$ mRNA level $(P<0 \cdot 05)$.

\section{Arginine catabolism-related gene expressions}

As shown in Fig. 2, supplementation with Arg did not affect ARGII mRNA level in the jejunum compared with supplementation with
ArgL under non-oxidative stress $(P>0.05)$. Injection of diquat significantly decreased ARGII mRNA level in the jejunum $(P<0 \cdot 05)$. Supplementation with Arg significantly reversed ARGII mRNA level induced by diquat to normal level in the jejunum $(P<0.05)$.

However, ArgH significantly decreased iNOS mRNA level in the jejunum compared with ArgL under non-oxidative stress $(P<0.05)$. Injection of diquat significantly decreased iNOS 

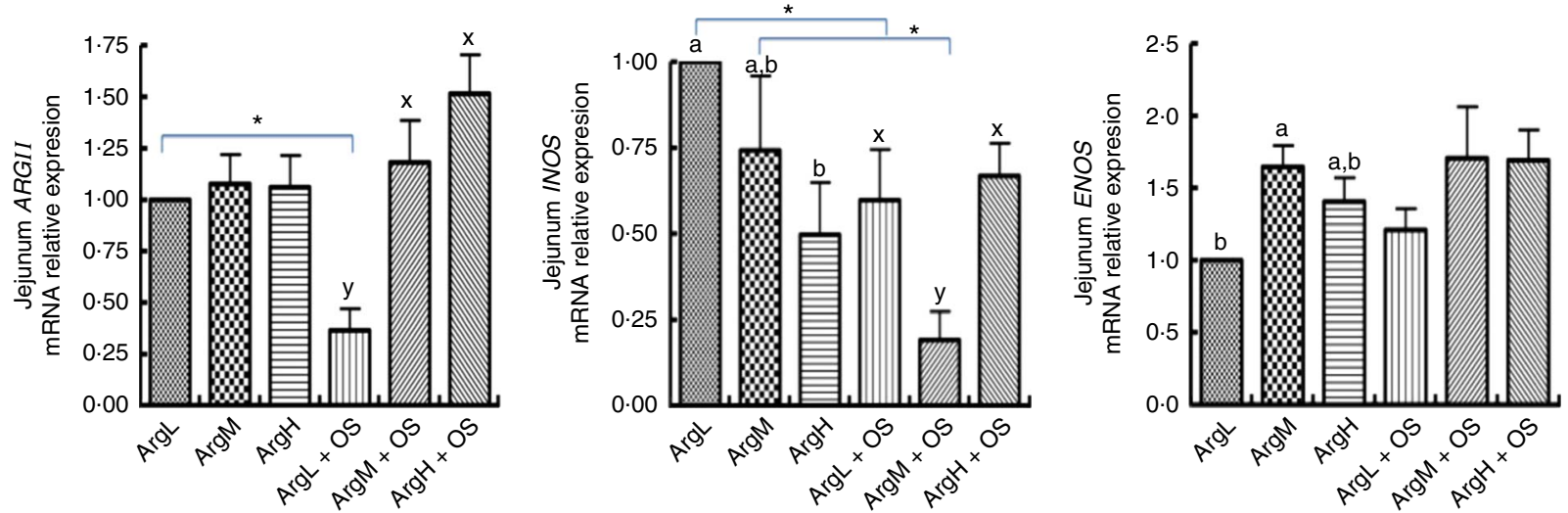

Fig. 2. Effects of arginine (Arg) supplementation and diquat injection on relative expressions of arginase II (ARGI), endothelial nitric oxide synthase (eNOS) and inducible nitric oxide synthase (iNOS) mRNA in the jejunum of piglets. ArgL, basal diet; ArgM, basal diet and supplementation with $0.8 \%$ synthetic L-Arg; ArgH, basal diet and supplementation with $1.6 \%$ synthetic L-Arg; OS, injection with diquat. Values are means $(n 6)$, with their standard errors represented by vertical bars. ${ }^{x, y}$ or ${ }^{\text {a,b }}$ Mean values with unlike superscript letters were significantly different $(P<0.05)$. ${ }^{*}$ Mean values were significantly different between two groups $(P<0.05)$.
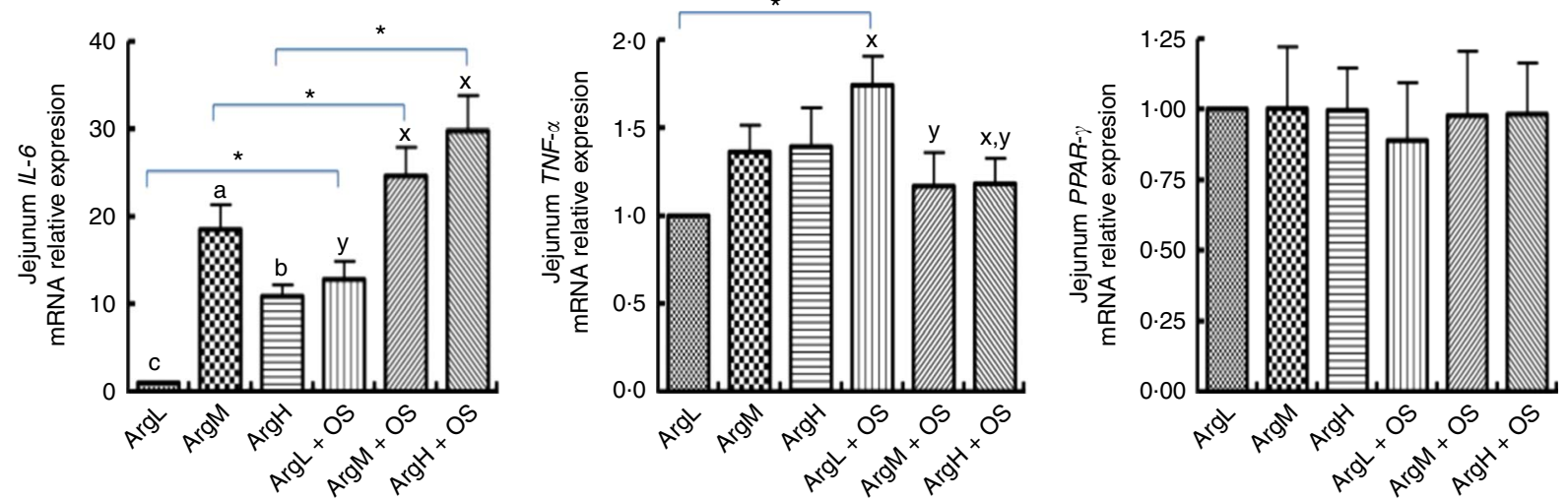

Fig. 3. Effects of arginine (Arg) supplementation and diquat injection on relative expressions of $I L-6, T N F-a$ and $P P A R-\gamma$ mRNA in the jejunum of weaned piglets. ArgL, basal diet; ArgM, basal diet and supplementation with $0.8 \%$ synthetic L-Arg; ArgH, basal diet and supplementation with $1.6 \%$ synthetic L-Arg; OS, injection with diquat. Values are means $(n 6)$, with their standard errors represented by vertical bars. ${ }^{x, y}$ or ${ }^{a, b}$ Mean values with unlike superscript letters were significantly different $(P<0.05)$. ${ }^{*}$ Mean values were significantly different between two groups $(P<0.05)$.

mRNA level in the jejunum $(P<0 \cdot 05)$ as well. ArgM significantly decreased $i N O S$ mRNA level in the jejunum with injection of diquat $(P<0.05)$ but ArgH did not have the same effect.

ArgM significantly increased eNOS mRNA level compared with ArgL under non-oxidative stress. Injection of diquat did not significantly affect $e N O S$ mRNA level in the jejunum $(P>0 \cdot 05)$.

\section{Inflammation-related gene expressions}

To investigate the possible protective effects of Arg on jejunum injury caused by oxidative stress induced by diquat, we quantified mRNA levels of $I L-6, T N F-\alpha$ and $P P A R-\gamma$ in the jejunum.

As shown in Fig. 3, ArgM and ArgH significantly increased $I L-6$ mRNA level in the jejunum of piglets, compared with ArgL with or without injection of diquat $(P<0 \cdot 05)$. Injection of diquat significantly increased $I L-6$ mRNA level in the jejunum of piglets $(P<0.05)$.

Supplementation with Arg did not affect TNF- $\alpha$ mRNA level in the jejunum under non-oxidative stress $(P>0.05)$. Injection of diquat significantly increased $T N F-\alpha$ mRNA level in the jejunum $(P<0.05)$. Supplementation with Arg could effectively relieve the increment of $T N F-\alpha$ mRNA level induced by diquat $(P<0.05)$.
Arg and injection of diquat had no effect on $P P A R-\gamma$ mRNA level in the jejunum of pigs $(P>0 \cdot 05)$.

\section{Discussion}

L-Arg is a multifunctional substance, which is not only a precursor for the synthesis of protein, NO, urea, polyamines and creatine but also regulates gene expression and antioxidation $^{(22,35-37)}$. Arg plays an important role in improving the growth performance and morphological development of the small intestine in suckling piglets ${ }^{(38)}$, weanling piglets ${ }^{(9)}$ and growing pigs fed a mould-contaminated diet ${ }^{(39)}$. Previous research studies showed that supplementation with Arg could increase the weight of the small intestine, enhance intestinal development ${ }^{(40)}$, improve microvascular development of the intestine in weanling piglets ${ }^{(41)}$ and alleviate the impairment induced by deoxynivalenol in growing pigs ${ }^{(42)}$. Intestinal function in piglets was greatly disturbed by oxidative stress, which resulted in reductions in nutrient absorption ${ }^{(7)}$. Our previous study proved that piglets suffered oxidative stress upon diquat injection ${ }^{(5)}$. Injection with diquat significantly increased the concentration of cortisol and MDA and decreased 
the activities of glutathione peroxidase and superoxide dismutase in the plasma of piglets ${ }^{(5)}$. At present, we have found that oxidative stress induced by diquat significantly decreased villus height, villus width and crypt depth in the jejunum and ileum. Supplementation with Arg significantly mitigated jejunum morphology impairment (e.g. lower villus width). Our previous study found that supplementation with Arg had a trend to increase ADFI of piglets under oxidative stress ${ }^{(5)}$. This result further proved that the increase in nutrient intake was beneficial to the health of piglets under oxidative stress. This result is also consistent with those from previous research studies that showed that supplementation with Arg can relieve dysfunction of the intestine caused by LPS-induced stress ${ }^{(43)}$. Besides, Viana et $a l{ }^{(44)}$ found that Arg was able to preserve barrier integrity and reduce bacterial translocation in the intestine of mice. We also detected the mRNA expression of inflammation-related genes and found that oxidative stress significantly increased $I L-6$ and TNF- $\alpha$ mRNA levels in the jejunum of piglets; supplementation with Arg could effectively relieve the increment of TNF- $\alpha$ mRNA level induced by oxidative stress. TNF- $\alpha$ is a proinflammatory cytokine involved in systemic inflammation $^{(45)}$. Further, research studies found TNF- $\alpha$ caused an increase in barrier permeability of the intestinal epithelium through activation of the ERK1/2 signalling pathway ${ }^{(46)}$. Therefore, it is reasonable to speculate that supplementing Arg in piglets can partially reduce oxidative injury by suppressing proinflammatory cytokine $T N F-\alpha$ expression in the jejunum.

Arg within the body is derived from the diet, endogenous synthesis and from turnover of proteins. The intestine plays a central role in maintaining Arg homoeostasis by providing exogenous Arg into the system. Animal studies showed that Arg was predominantly transported across the intestinal membrane via an $\mathrm{Na}^{+}$-independent system: that is, via $\mathrm{y}^{+} \mathrm{CAT}$ isoforms $^{(47,48)}$. In this study, we measured CAT expression and found that oxidative stress induced by diquat significantly increased gene expression of CAT-1, CAT-2 and CAT-3 in the jejunum of piglets. Duan et $a l^{(6)}$ found that oxidative stress induced by injection of $\mathrm{H}_{2} \mathrm{O}_{2}$ tended to increase mRNA levels of anionic amino acid transporters and that dietary Arg supplementation enhances intestinal anionic amino acid transporter expression ${ }^{(39)}$. Supplementation with Arg increased gene expression of $C A T-2$ but not $C A T-1$ and $C A T-3$ in the jejunum under the non-oxidative stress condition. However, under oxidative stress situations, supplementation with Arg significantly suppressed the increase in gene expression of CAT-1 and CAT-2 induced by oxidative stress but not of CAT-3. These results suggest that Arg transport is very complicated and influenced by many factors. The regulatory mechanisms of Arg absorption could be mainly in the following two ways. First, Arg absorption was mediated by the level of substrate ${ }^{(36)}$. In this study, increasing the concentration of Arg in diet significantly increased the gene expression of $C A T-2$ under non-oxidative stress conditions and $C A T-3$ in oxidative stress conditions in the jejunum, respectively. On the other hand, the gene expressions of $C A T-1, C A T-2$ and $C A T-3$ in the jejunum were increased when the concentration of Arg in plasma was reduced by oxidative stress. Second, Arg absorption was mediated by the cytokine TNF- $\alpha$ pathway ${ }^{(49)}$. In this study, oxidative stress significantly increased the expression of the $T N F-\alpha$ gene as well as of CAT-1, CAT-2 and CAT-3 genes, whereas supplementation with Arg significantly inhibited the expression of $T N F-\alpha$ and CAT-1. Research studies indicated that $T N F-\alpha$ increased Arg transport in a time- and dose-dependent manner in human vascular endothelium by activation of protein kinase $\mathrm{C}^{(49)}$. PKC regulated Arg transport activity via a mechanism of activating transporter mRNA and translational processes in Caco-2 intestinal cells ${ }^{(50)}$. The data from this study suggested that TNF- $\alpha$ was involved in the regulation of Arg transport mainly by affecting the activity of CAT- 1 but not CAT-2 and CAT-3 in the jejunum under oxidative stress.

The small intestine is the most important site not only for Arg absorption but also for metabolism of Arg. Arg homoeostasis is achieved principally through regulation of Arg catabolism. Both NOS and arginase use Arg as a common substrate, and arginase may down-regulate NO production by competing with NOS for Arg. In this study, oxidative stress significantly decreased $i N O S$ and ARGII mRNA levels in the jejunum, which could be a result of the low availability of Arg. This conclusion is supported by the observation that Arg can regulate gene expression as a substrate for enzymes ${ }^{(36)}$ and that Arg deprivation results in decreased expression of $i N O S^{(51)}$. Supplementation with Arg could significantly increase eNOS and ARGII mRNA levels but not iNOS levels, probably because elevated $A R G I I$ expression inhibited the expression of $i N O S^{(52)}$. A previous study reported that the large amount of NO synthesised by iNOS lead to arthritis in humans ${ }^{(53)}$, which indicated that the role of NO in vivo depended on its origin. Hence, in this study, supplementation with Arg could significantly increase the expression of eNOS but not iNOS, which could be one of the reasons for relieving the influences of oxidative stress with Arg supplementation. In conditions such as oxidative stress, which increase the metabolic demand for Arg beyond the maximum Arg synthetic capacity, dietary Arg supplementation is necessary. Hu et al. ${ }^{(54)}$ also studied the safe dose of Arg supplementation in weaned pigs and indicated that supplementing up to $2 \% \mathrm{~L}$-Arg (as either L-Arg- $\mathrm{HCl}$ or L-Arg-base) in the diet for $91 \mathrm{~d}$ did not have any adverse effect on postweaning pigs. However, Arg is expensive; therefore, it is important to research the proper dose of Arg to be supplemented in different situations. In this study, ArgM showed the same effects as $\mathrm{ArgH}$ in relieving oxidative stress in the intestine of piglets; thus, ArgM could be the best choice in this model, and the related research studies deserve more attention in the future.

In conclusion, oxidative stress induced by diquat can influence absorption and metabolism of Arg in the jejunum of weaned piglets, and dietary supplementation with Arg has beneficial effects for intestinal health and functions through improvement in the morphology of the intestine, regulation of Arg availability and reduction of inflammatory cytokine levels. This study illustrates that dietary Arg supplementation in piglets is necessary for increasing the metabolic demand of Arg in piglets under oxidative stress. Adequate L-Arg provision may be a novel and effective means to ameliorate oxidative injury in the small intestine. 


\section{Acknowledgements}

This project was jointly financed by the National Natural Science Foundation of China (31501963), the Science and Technology Support Program of Sichuan Province (2013NZ0056, 2016NZ006) and by the earmarked fund for China Agriculture Research System (no. CARS-36).

The author contributions are as follows: P. Z., Y. L. G. T. and Q. Z. conducted the experiments. B. Y. and D. C. participated in the design of the study. J. L. and Z. H. assisted in analyses. J. H. and J. Y. assisted in manuscript preparation. L. C and X. M. assisted with all data analyses.

The authors declare that there are no conflicts of interest.

\section{References}

1. Circu ML \& Aw TY (2012) Intestinal redox biology and oxidative stress. Semin Cell Dev Biol 23, 729-737.

2. Yin J, Ren W, Liu G, et al. (2013) Birth oxidative stress and the development of an antioxidant system in newborn piglets. Free Radic Res 47, 1027-1035.

3. Lykkesfeldt J \& Svendsen O (2007) Oxidants and antioxidants in disease: oxidative stress in farm animals. Vet $J \mathbf{1 7 3}$, 502-511.

4. Jiang SZ, Yang ZB, Yang WR, et al. (2011) Effects of purified zearalenone on growth performance, organ size, serum metabolites, and oxidative stress in postweaning gilts. J Anim Sci 89, 3008-3015

5. Zheng P, Yu B, He J, et al. (2013) Protective effects of dietary arginine supplementation against oxidative stress in weaned piglets. Br J Nutr 109, 2253-2260.

6. Duan J, Yin J, Ren W, et al. (2016) Dietary supplementation with l-glutamate and 1-aspartate alleviates oxidative stress in weaned piglets challenged with hydrogen peroxide. Amino Acids 48, 53-64.

7. Yin J, Liu M, Ren W, et al. (2015) Effects of dietary supplementation with glutamate and aspartate on diquat-induced oxidative stress in piglets. PLOS ONE 10, e0122893.

8. Askew EW (1995) Environmental and physical stress and nutrient requirements. Am J Clin Nutr 61, 631S-637S.

9. He Q, Tang H, Ren P, et al. (2011) Dietary supplementation with L-arginine partially counteracts serum metabonome induced by weaning stress in piglets. J Proteome Res 10, $5214-5221$.

10. Yang H, Xiong X, Wang X, et al. (2016) Effect of weaning on intestinal crypt epithelial cells in piglets. Sci Rep 6, 36939.

11. Yin J, Duan J, Cui Z, et al. (2015) Hydrogen peroxide-induced oxidative stress activates NF- $\mathrm{KB}$ and Nrf2/Keap1 signals and triggers autophagy in piglets. RSC Adv 5, 15479.

12. Tang Y, Li J, Li F, et al. (2015) Autophagy protects intestinal epithelial cells against deoxynivalenol toxicity by alleviating oxidative stress via IKK signaling pathway. Free Radic Biol Med 89, 944-951.

13. Yin J, Wu M, Li Y, et al. (2017) Toxicity assessment of hydrogen peroxide on Toll-like receptor system, apoptosis, and mitochondrial respiration in piglets and IPEC-J2 cells. Oncotarget 8, 3124-3131.

14. Jeynes BJ \& Altmann G (1975) Region of mitochondrial division in the epithelium of the small intestine of the rat. Anat Rec 182, 289-296.

15. Figueira TR, Barros MH, Camargo AA, et al. (2013) Mitochondria as a source of reactive oxygen and nitrogen species: from molecular mechanisms to human health. Antioxid Redox Signal 18, 2029-2074.
16. Duan J, Yin J, Wu M, et al. (2014) Dietary glutamate supplementation ameliorates mycotoxin-induced abnormalities in the intestinal structure and expression of amino acid transporters in young pigs. PLOS ONE 9, e112357.

17. Hussain T, Tan B, Yin Y, et al. (2016) Oxidative stress and inflammation: what polyphenols can do for us? Oxid Med Cell Longev 4, e7432797.

18. Suschek CV, Schnorr O, Hemmrich K, et al. (2003) Critical role of L-arginine in endothelial cell survival during oxidative stress. Circulation 107, 2607-2614.

19. Lin CC, Tsai WC, Chen JY, et al. (2008) Supplements of $\mathrm{L}$-arginine attenuate the effects of high-fat meal on endothelial function and oxidative stress. Int J Cardiol 127, 337-341.

20. Maggio M, Guralnik JM, Longo DL, et al. (2006) Interleukin-6 in aging and chronic disease: a magnificent pathway. J Gerontol A Biol Sci Med Sci 61, 575-584.

21. Southern LL \& Baker DH (1983) Arginine requirement of the young pig. J Anim Sci 57, 402-412.

22. Wu G, Bazer FW, Davis TA, et al. (2007) Important roles for the arginine family of amino acids in swine nutrition and production. Livest Sci 112, 8-22.

23. Closs EI, Simon A, kony NV, et al. (2004) Plasma membrane transporters for arginine. J Nutr 134, 2752S-2759S.

24. Pan M, Choudry HA, Epler MJ, et al. (2004) Arginine transport in catabolic disease states. J Nutr 134, 2826S-2829S.

25. Wu G, Borbolla AG \& Knabe DA (1994) The uptake of glutamine and release of arginine, citrulline and proline by the small intestine of developing pigs. J Nutr 124, 2437-2444.

26. Wu G, Davis PK, Flynn NE, et al. (1997) Endogenous synthesis of arginine plays an important role in maintaining arginine homeostasis in postweaning growing pigs. $J$ Nutr 127, 2342-2349.

27. Morris SM (2000) Regulation of arginine availability and its impact on NO synthesis. In Nitric Oxide: Biology and Pathobiology, pp. 187-197 [LJ Ignarro, editor]. San Diego, CA: Academic Press.

28. Mori M \& Gotoh T (2000) Regulation of nitric oxide production by arginine metabolic enzymes. Biochem Biophys Res Commun 275, 715-719.

29. Wu G, Bazer FW, Davis TA, et al. (2009) Arginine metabolism and nutrition in growth, health and disease. Amino Acids 37, $153-168$.

30. Zheng P, Yu B, Lv M, et al. (2010) Effects of oxidative stress induced by diquat on arginine metabolism of postweaning pigs. Asian-Australas J Anim Sci 23, 98-106.

31. Ertingshausen G, Adler H, Reichler A, et al. (1969) Fully automated high-speed ion-exchange chromatography of amino acids. J Chromatogr A 42, 355-366.

32. Luna LG (1968) Manual of Histologic Staining Methods of the Armed Forces Institute of Pathology. New York: McGraw-Hill Book Company.

33. Hillig A, Jørgensen C, Cirera S, et al. (2007) Selection of reference genes for gene expression studies in pig tissues using SYBR green qPCR. BMC Mol Biol 8, 67-73.

34. Pfaffl MW (2001) A new mathematical model for relative quantification in real-time RT-PCR. Nucleic Acids Res 29, 2002-2007.

35. Montanez R, Rodriguez-Caso C, Sanchez-Jimenez F, et al. (2008) In silico analysis of arginine catabolism as a source of nitric oxide or polyamines in endothelial cells. Amino Acids 34, 223-229.

36. Morris SM (2006) Arginine: beyond protein. Am J Clin Nutr 83, 508S-512S.

37. Ma X, Zheng C, Hu Y, et al. (2015) Dietary L-arginine supplementation affects the skeletal longissimus muscle proteome in finishing pigs. PLOS ONE 10, e0117294. 
38. Kim SW, McPherson RL \& Wu G (2004) Dietary arginine supplementation enhances the growth of milk-fed young pigs. J Nutr 134, 625-630.

39. Yin J, Ren W, Duan J, et al. (2014) Dietary arginine supplementation enhances intestinal expression of SLC7A7 and SLC7A1 and ameliorates growth depression in mycotoxinchallenged pigs. Amino Acids 46, 883-892.

40. Yao K, Guan S, Li T, et al. (2011) Dietary L-arginine supplementation enhances intestinal development and expression of vascular endothelial growth factor in weanling piglets. Br J Nutr 105, 703-709.

41. Zhan Z, Ou D, Piao X, et al. (2008) Dietary arginine supplementation affects microvascular development in the small intestine of early-weaned pigs. J Nutr 138, 1304-1309.

42. Wu L, Wang W, Yao K, et al. (2013) Effects of dietary arginine and glutamine on alleviating the impairment induced by deoxynivalenol stress and immune relevant cytokines in growing pigs. PLOS ONE 8, e69502.

43. Liu Y, Huang J, Hou Y, et al. (2008) Dietary arginine supplementation alleviates intestinal mucosal disruption induced by Escherichia coli lipopolysaccharide in weaned pigs. Br J Nutr 100, 552-560.

44. Viana ML, Santos RGC, Generoso SV, et al. (2010) Pretreatment with arginine preserves intestinal barrier integrity and reduces bacterial translocation in mice. Nutrition $\mathbf{2 6}, 218-223$.

45. Ma T, Boivin M, Ye D, et al. (2005) Mechanism of TNF- $\alpha$ modulation of $\mathrm{CacO}-2$ intestinal epithelial tight junction barrier: role of myosin light-chain kinase protein expression. Am J Physiol Gastrointest Liver Physiol 288, G422-G430.
46. Al-Sadi R, Guo S, Ye D, et al. (2013) TNF- $\alpha$ modulation of intestinal epithelial tight junction barrier is regulated by ERK1/2 activation of Elk-1. Am J Pathol 183, 1871-1884.

47. White MF (1985) The transport of cationic amino acids across the plasma membrane of mammalian cells. Biochem Biophys Acta 822, 355-374.

48. Stevens BR (1992) Amino acids transport in intestine. In Mammalian Amino Acid Transport, 149-163 [MS Kilberg and D Haussinger, editors]. New York, NY: Plenum Press.

49. Pan M, Wasa M, Lind DS, et al. (1995) TNF- $\alpha$ stimulated arginine transport by human vascular endothelium requires activation of protein kinase C. Ann Surg 221, 590-601.

50. Pan M \& Stevens BR (1995) Protein kinase C-dependent regulation of L-arginine transport activity in Caco-2 intestinal cells. Biochim Biophys Acta 1239, 27-32.

51. El-Gayar S, Thuring-Nahler H, Pfeilschifter J, et al. (2003) Translational control of inducible nitric oxide synthase by IL-13 and arginine availability in inflammatory macrophages. J Immunol 171, 4561-4568.

52. Lee J, Ryu H, Ferrante RJ, et al. (2003) Translational control of inducible nitric oxide synthase expression by arginine can explain the arginine paradox. Proc Natl Acad Sci U S A 100, 4843-4848.

53. Meininger CJ, Kelly KA, Li H, et al. (2000) Glucosamine inhibits inducible nitric oxide synthesis. Biochem Biophys Res Commun 279, 234-239.

54. Hu S, Li X, Rezaei R, et al. (2015) Safety of long-term dietary supplementation with L-arginine in pigs. Amino Acids 47, 925-936. 